\title{
- \\ III Encontro latinoamericano de intercâmbio universitário em psicologia
}

\author{
Jorge Castellá Sarriera \\ Universidade Federal do Rio Grande do Sul
}

\section{Um pouco de história}

Os Encontros Latinoamericanos de Intercâmbio Universitário em Psicologia vêm sendo realizados bianualmente junto com os simpósios da Associação Nacional de Pesquisa e Pós-graduação em Psicologia (ANPEPP). Esse evento reúne a maior parte dos docentes e pesquisadores da Psicologia do Brasil nos seus mais de 60 Programas de Pós-graduação, agregando mais de 1000 participantes. Desde o início dos Encontros, os professores Sílvia Helena Koller (UFRGS), Norberto Abreu (UnB) e Jorge Castellá Sarriera (UFRGS) foram os coordenadores desses eventos.

O primeiro Encontro ocorreu em 2006, na cidade Florianópolis-SC, por ocasião do XI Simpósio de Pesquisa e Intercâmbio Científico da ANPEPP, cujo tema central foi: Formação: Ensino e Pesquisa na Pós-graduação em Psicologia. O evento abordou a necessidade e possibilidades de estreitamento de vínculos entre os pesquisadores brasileiros e os centros de formação e pesquisa da América Latina.

O segundo evento celebrou-se em Natal-RN, em 2008, junto com o XII Simpósio de Pesquisa e Intercâmbio Científico da ANPEPP com o lema Conhecimento em Psicologia no Brasil: expansão e avaliação.

Nos dois dias do II Encontro Latinoamericano, seis psicólogos representantes da pós-graduação e pesquisa da Colômbia, Peru, Chile, Argentina, Uruguai e Paraguai, expuseram a história e o status atual dos cursos de pós-graduação em psicologia nos seus países, interagindo com nossos pesquisadores que tiveram maior conhecimento das dificuldades e possibilidades em cada país e das possíveis aproximações para intercâmbio.

O III Encontro Latinoamericano de Intercâmbio Universitário em Psicologia, cujos temas em discussão resultantes de uma de suas mesas redondas ora se apresentam, ocorreu em 2010, no Simpósio da ANPEPP em Fortaleza. Teve como finalidade conhecer as políticas científicas, os programas e parcerias do sistema de ciência e tecnologia de países latinoamericanos, com possibilidades de inserção da área de psicologia para o estabelecimento de parcerias, redes de pesquisa e intercâmbio. Além disso, foi foco do Encontro, analisar os principais desafios entre países latinoamericanos no campo da pesquisa e de formação de pós-graduação em psicologia, promover relações acadêmicas entre os docentes-pesquisadores dos programas brasileiros de pós-graduação em psicologia e representantes de universidades de toda a América Latina.

A primeira Mesa Redonda, "Políticas Científicas e Intercâmbio Latinoamericano", teve como foco conhecer as prioridades em políticas científicas e programas de desenvolvimento em pesquisa, assim como as possibilidades de estimular relações entre países vizinhos através de projetos de apoio conjunto para a investigação e intercâmbio. Foram os palestrantes o Dr. Glaucius Oliva (atual Presidente do $\mathrm{CNPq}$ ), que discorreu sobre as políticas científicas, de produção e formação em pesquisa no Brasil e apresentando a trajetória de auxílios e bolsas e novidades sobre políticas de apoio à pesquisa; em seguida, o Dr. Hugo Sirkin (Secretário de Ciência e Tecnologia da Universidade de Buenos Aires), apresentou a política de incremento para auxílios e bolsas nos últimos anos; por fim, palestrou o Dr. Luis Victor Leopold (Universidad de La Republica del Uruguai), fazendo um relato do processo de formação da pós-graduação em psicologia na Universidade Oriental do Uruguai, assim como os processos de avaliação do curriculum formativo da Psicologia.

A segunda Mesa Redonda cujos escritos apresentamos nos “Temas em Discussão” tratou sobre os "Caminhos do Desenvolvimento Científico e Intercâmbio Latinoamericano em Psicologia”, sendo o objetivo da mesa conhecer as trajetórias de três países latinoamericanos, Colômbia, Cuba e Paraguai, no tocante ao desenvolvimento histórico da Psicologia, à formação de pesquisadores, produção científica, áreas de excelência, desafios, prioridades atuais e possibilidades de intercâmbio. Foram os palestrantes o Dr. Francisco Morales Calatayud (Cuba), o Dr. Wilson López (Colombia), e a Dra. Norma Coppari (Paraguai). Cada uma das palestras aqui transformadas em artigos evidencia a situação da Psicologia em seus respectivos países, especialmente a trajetória da psicologia em Cuba e no Paraguai.

Francisco Morales Calatayud desenvolveu a palestra sobre a Investigación en psicología y Psicología de la Salud en Cuba: experiencias y potencialidades, que se apresenta a seguir em forma de artigo neste número.

O Dr. Luis Victor Leopold (UdelaR - Uruguai) expôs a trajetória seguida pela Faculdade de Psicologia da Universidade de la República do Uruguai e as tentativas da procura atual de um modelo de pós-graduação autônomo, orientado às necessidades e características do seu país. 
A psicóloga Dra. Norma B. Coppari, das Universidades Nacional e Católica de Asunción, Paraguai, desenvolveu o histórico da formação em psicologia e os caminhos que vem sendo seguidos em termos de consolidar a pesquisa e a pós-graduação. Neste sentido, apresenta-se também na íntegra a referida palestra.

O Dr. Wilson López traz um estudo sobre a Rede de Revistas Científicas da América Latina e do Caribe (RedALyC) apontando a falta de conhecimento e de articulação entre os pesquisadores latino-americanos. Por meio de uma análise das citações e referências dos artigos na Rede, verifica-se que os latinoamericanos citam basicamente autores americanos ou europeus. O artigo reitera a importância do intercâmbio e a produção de conhecimento entre pesquisadores psicólogos da América Latina.

Desejamos que eventos como os Encontros Latinoamericanos de Intercâmbio Universitário em Psicologia possam continuar estimulando a troca, o mútuo conhecimento e o intercâmbio entre pesquisadores psicólogos latinoamericanos. Por fim, agradecemos à CAPES que possibilitou o Evento, à ANPEPP que deu acolhimento ao mesmo e à Revista Estudos de Psicologia (Natal) que disponibilizou a publicação da Separata.

Jorge Castellá Sarriera

Coordenador do III Encontro Latinoamericano de Intercâmbio Acadêmico em Psicologia

Endereço para correspondência: Rua Alvares Machado, 120/502. CEP: 90630-010. Porto Alegre-RS

E-mail: sarriera@terra.com.br Fone: (51)8183-9023 